Supporting Information

\title{
Exceptional nuclease resistance of paranemic crossover (PX) DNA and crossover-dependent biostability of DNA motifs
}

\author{
Arun Richard Chandrasekaran, ${ }^{1 *}$ Javier Vilcapoma, ${ }^{1}$ Paromita Dey, ${ }^{1,2}$ \\ Siu Wah Wong-Deyrup, ${ }^{1,2}$ Bijan K. Dey ${ }^{1,2}$ Ken Halvorsen ${ }^{1 *}$
}

\footnotetext{
${ }^{1}$ The RNA Institute, University at Albany, State University of New York, Albany, NY, USA.

${ }^{2}$ Department of Biology, University at Albany, State University of New York, Albany, NY, USA.
}

Corresponding authors: arun@albany.edu (ARC) or khalvorsen@albany.edu (KH) 


\section{This PDF file includes:}

\section{Materials and methods}

- Oligonucleotide sequences

- Formation of DNA complexes

- Polyacrylamide gel electrophoresis (PAGE)

- UV melting experiments

- Circular dichroism experiments

- DNase I assay
- Exonuclease assays

- Decay kinetics of structures with nucleases

- Stability test in biofluids

- Cell culture and differentiation assay

- MTT assay

- RNA isolation and qRT-PCR

\section{Additional experimental results}

Figure S1. Design and sequences of DNA structures.

Figure S2. Stepwise assembly of PX DNA.

Figure S3. Ferguson plot analysis.

Figure S4. Strand incorporation in PX DNA.

Figure S5. UV melting analysis.

Figure S6. Stability of motifs at physiological temperature.

Figure S7. DNase I treatment of duplex, DX and PX motifs.

Figure S8. Digestion products PX DNA.

Figure S9. PX DNA resistance against DNase I.

Figure S10. Resistance of tested structures to exonucleases.

Figure S11. Enzyme activity of different nucleases on PX DNA.

Figure S12. Analysis of shorter time points for incubation with exonucleases.

Figure S13. Decay kinetics of structures in different nucleases.

Figure S14. Cell viability with different concentrations of PX DNA.

Figure S15. Design and sequences of the JX DNA motifs.

Figure S16. Assembly of $J X_{n}$ motifs.

Figure S17. Stability of $\mathrm{JX}_{\mathrm{n}}$ motifs at $37^{\circ} \mathrm{C}$.

Figure S18. DNase I resistance of $\mathrm{JX}_{\mathrm{n}}$ motifs.

Figure S19. Stability in fetal bovine serum (FBS).

Figure S20. Stability in human serum and urine.

Figure S21. Stability of duplex, DX and PX motifs in different amounts of FBS. 


\section{Materials and methods}

\section{Oligonucleotide sequences}

All oligonucleotides were purchased from IDT, Inc. Full sequences (5'-3') are listed below. Strand routing for duplex, DX and PX structures are shown in Figure S1, and $\mathrm{JX}_{1}, \mathrm{JX}_{2}$ and $\mathrm{JX}_{3}$ in Figure S15.

DC1A: 5' -GTGGTGTCGCAACAGATATGTGTAGGCACCGAATCACT-3'

DC1B : 5'-AGTGATTCGGTGCCTACACATATCTGTTGCGACACCAC-3'

DX1: 5'-AGTGATTCGGTGCCTACACATATCTGTTGCGACACCAC-3'

DX2 : 5'-GTGGTGTCGCAACAGACACAATACTTCACCGAATCACT-3'

DX3 : 5'-ACTAGATCATCAATGCTATGTGTAGGGTTAGACCTGAG-3'

DX4: 5'-CTCAGGTCTAACAAGTATTGTGGCATTGATGATCTAGT-3'

PX1: 5'-GTGGTATCATCAATGCTATGTGTAGGCTTAGACCTGAG-3'

PX2: 5'-ACTAGGTCGCAACAGACACAATACTTGACCGAATCACT-3'

PX3 : 5'-AGTGAGTCTAACAAGTCACATATCTGTGATGATCTAGT-3'

PX4 : 5'-CTCAGTTCGGTGCCTAATTGTGGCATTTGCGACACCAC-3'

JX-A: 5' -GTGGTATCATCAATGCCACAATACTTGACCGAATCACT-3 '

JX-B : 5' -ACTAGGTCGCAACAGATATGTGTAGGCTTAGACCTGAG-3'

JX-C: 5' -AGTGAGTCTAACAAGTATTGTGGCATTTGCGACACCAC-3'

JX-D: 5'-CTCAGTTCGGTGCCTACACATATCTGTGATGATCTAGT-3'

JX-E : 5'-AGTGAGTCTAACAAGTATTGTGGCATTGATGATCTAGT-3'

JX-F : 5'-CTCAGTTCGGTGCCTACACATATCTGTTGCGACACCAC-3'

Fluorophore-labeled strands:

PX1: 5'-FAM-GTGGTATCATCAATGCTATGTGTAGGCTTAGACCTGAG-3'

PX2 : 5'-FAM-ACTAGGTCGCAACAGACACAATACTTGACCGAATCACT-3'

PX3 : 5'-FAM-AGTGAGTCTAACAAGTCACATATCTGTGATGATCTAGT-3'

PX4 : 5'-FAM-CTCAGTTCGGTGCCTAATTGTGGCATTTGCGACACCAC-3' 


\section{Assembly of DNA complexes}

To form the different DNA complexes (duplex, DX, PX and JX ), we mixed the specific component strands in equimolar ratios to a final concentration of $1 \mu \mathrm{M}$ in Tris-Acetic-EDTA- $\mathrm{Mg}^{2+}\left(\mathrm{TAE} / \mathrm{Mg}^{2+}\right)$ buffer containing $40 \mathrm{mM}$ Tris base $(\mathrm{pH} 8.0), 20 \mathrm{mM}$ acetic acid, $2 \mathrm{mM}$ EDTA, and $12.5 \mathrm{mM}$ magnesium acetate. The DNA solution was slowly cooled from $95^{\circ} \mathrm{C}$ to $20^{\circ} \mathrm{C}$ by placing the tubes in 2 liters of hot water in a Styrofoam box for 48 hours to facilitate hybridization.

\section{Polyacrylamide gel electrophoresis (PAGE)}

Non-denaturing gels containing 8-10\% polyacrylamide (29:1 acrylamide/bisacrylamide) were run at 4 ${ }^{\circ} \mathrm{C}\left(100 \mathrm{~V}\right.$, constant voltage) in 1× TAE/Mg ${ }^{2+}$ running buffer. Gels were stained in $1 \mathrm{X} \mathrm{TAE} / \mathrm{Mg}^{2+}$ buffer containing $0.5 \times$ GelRed (Sigma). Denaturing gels (15\% polyacrylamide and 8.3 M urea) were run at 20 ${ }^{\circ} \mathrm{C}(100 \mathrm{~V}$, constant voltage). Running buffer consisted of $89 \mathrm{mM}$ Tris, $89 \mathrm{mM}$ boric acid, $2 \mathrm{mM}$ EDTA (TBE). Imaging was done on a Bio-Rad Gel Doc XR+ imager using the default settings for GelRed with UV illumination. Gel images were exported as 12-bit images and quantified using ImageJ. Quantification was done using the highest exposure image that did not contain saturated pixels in the band of interest.

\section{UV melting experiments}

Experiments were performed in a Cary 300 UV-Visible Spectrophotometer equipped with a temperature controller, using $1 \mu \mathrm{M}$ annealed complexes. Melting curves were acquired at $260 \mathrm{~nm}$ by heating and cooling from $5{ }^{\circ} \mathrm{C}$ to $85^{\circ} \mathrm{C}$ at a rate of $0.2^{\circ} \mathrm{C} / \mathrm{min}$.

\section{Circular dichroism experiments}

CD spectra was collected on $5 \mu \mathrm{M}$ samples annealed in $1 \times \mathrm{TAE} / \mathrm{Mg}^{2+}$. Experiments were performed on a Jasco-815 CD spectrometer at room temperature in a quartz cell with a 10-mm path length. CD spectra were collected from 380 to $200 \mathrm{~nm}$ and with a scanning speed of $100 \mathrm{~nm} / \mathrm{min}$. The bandwidth was $1.0 \mathrm{~nm}$, and the digital integration time was $1.0 \mathrm{~s}$. 


\section{DNase I assay}

Annealed DNA complexes (at $1 \mu \mathrm{M}$ ) were first mixed with DNase I reaction buffer (final of $1 \times$ ). DNase I enzyme was purchased from New England Biolabs (Catalog \# M0303S), and according to the vendor, is isolated from a recombinant $E$. Coli strain carrying an MBP fusion clone of bovine pancreatic DNase I. Dilutions of DNase I enzyme to different units was made in nuclease-free water. For the DNase I assay, $1 \mu \mathrm{L}$ of the enzyme was added to $10 \mu \mathrm{L}$ of the sample containing DNase I reaction buffer. Samples were incubated at $37^{\circ} \mathrm{C}$ for different time intervals. Incubated samples were mixed with gel loading dye containing bromophenol blue and $1 \times \mathrm{TAE} / \mathrm{Mg}^{2+}$ and run on non-denaturing PAGE to analyze degradation over time.

\section{Exonuclease assays}

RecBCD (M0345S), T7 exonuclease (M0263S) and T5 exonuclease (M0363S) were purchased from New England Biolabs. Annealed DNA complexes (at $1 \mu \mathrm{M})$ were first mixed with specific reaction buffer for each enzyme (final of $1 \times$ ). Dilutions of enzymes to different units was made in nuclease-free water. For the exonuclease assay, $1 \mu \mathrm{L}$ of the enzyme was added to $10 \mu \mathrm{L}$ of the sample containing the reaction buffer. Samples were incubated for different time intervals at specific conditions prescribed for each enzyme by the vendor. Samples were mixed with gel loading dye containing bromophenol blue and $1 \times$ TAE/Mg ${ }^{2+}$ and run on non-denaturing PAGE to analyze degradation over time.

\section{Decay kinetics of structures with nucleases}

Annealed structures (duplex, DX and PX) were incubated with nucleases for different durations at conditions described above. In some cases, structures were degraded completely within 2 mins. For such cases, we used a slightly modified timed assay to get shorter time points within 2 mins, by mixing the enzyme, counting down the time, and loading it to the gel (Figure S12). The triplicates for these were performed in separate gels so there is no lag in the time taken to load multiple samples on one gel. For the T7 exonuclease, digestion of duplex was very fast (100\% degraded in 30 seconds). To obtain an intermediate time point before the duplex was completely degraded, we added the enzyme to the sample and used it right away for gel analysis. This gave us a short time point of $\sim 15$ seconds (time taken to move tube, add loading dye and load on gel), where we were able to see remnant duplex (Figure S12). 
For each structure, we performed time series experiments in triplicates and quantified bands corresponding to structures for each incubation time. We then fit an exponential decay model in Origin Lab for each replicate and obtained time constants $(\tau)$ for each structure in different nucleases. We averaged the time constants obtained from each replicate and obtained standard deviations of these values. Representative exponential decay fits and average time constants for duplex, DX and PX in four different exonucleases are shown in Figure S13.

For calculating the biostability enhancement factor of PX DNA over the DX and duplex structures, we divided the time constants of PX by DX or duplex (Figure 2f). Final errors in PX/DX and PX/duplex were propagated as uncertainty values from errors in time constants for PX, DX and duplex structures.

\section{Stability test in biofluids}

Pooled normal human serum and human urine were purchased from Innovative Research Inc. Fetal bovine serum (FBS), human serum or urine was added to annealed DNA complexes to be at a final concentration of $10 \%$. Typically, we added $1 \mu \mathrm{L}$ of the biofluid to $9 \mu \mathrm{L}$ of the annealed samples and incubated them at $37^{\circ} \mathrm{C}$ for different time intervals. Incubated samples were mixed with gel loading dye containing bromophenol blue and $1 \times \mathrm{TAE} / \mathrm{Mg}^{2+}$ and run on non-denaturing PAGE to analyze degradation over time. All experiments were conducted in triplicates.

\section{Cell culture and differentiation assay}

Mouse myoblast cell line (C2C12) and human cell line (HeLa) were acquired from the American Type Culture Collection (ATCC). Cells were maintained at subconfluent densities in grown medium (GM) at $37{ }^{\circ} \mathrm{C}$ in a tissue culture incubator with a constant supply of $5 \% \mathrm{CO}_{2}$. GM consists of Dulbecco's modified Eagle medium (DMEM; Gibco) supplemented with 10\% FBS and 1× antibiotic-antimycotic (Life Technologies). For myogenic differentiation assay, the myoblast cells were grown to about $70 \%$ confluency, washed with phosphate-buffered saline (PBS), and cultured with differentiation medium (DM). DM consists of DMEM containing $2 \%$ heat-inactivated horse serum (HyClone) and $1 \times$ antibioticantimycotic. Cells were harvested while growing in GM and after 48 and 96 hours (DM2 and DM4, respectively) in DM. For the control set, cells were incubated with $1 \times \mathrm{TAE} / \mathrm{Mg}^{2+}$ and for the test set, cells were incubated with $100 \mathrm{nM}$ PX DNA assembled in $1 \times \mathrm{TAE} / \mathrm{Mg}^{2+}$. Experiments were conducted as biological triplicates with individual differentiation tests for each replicate. 


\section{MTT assay}

MTT assay was carried out using Vybrant ${ }^{\circledR}$ MTT Cell Proliferation Assay Kit (Invitrogen) following the manufacturer's instruction. Briefly, the cells were plated and the next day medium was removed and replaced with $100 \mu \mathrm{L}$ of fresh culture medium without phenol red. $10 \mu \mathrm{L}$ of the $12 \mathrm{mM}$ MTT stock solution was then added to each well and incubated at $37^{\circ} \mathrm{C}$ for 4 hours. After labeling the cells with MTT, all the medium and reagent mixtures were removed but $25 \mu \mathrm{L}$ of medium and reagent mixtures were left in each well. Then, $50 \mu \mathrm{L}$ of DMSO was added to each well, mixed thoroughly and incubated at $37^{\circ} \mathrm{C}$ for 10 minutes. The samples were mixed well once again and absorbance was read at $540 \mathrm{~nm}$ using a plate reader. For the control set, cells were incubated with $1 \times \mathrm{TAE} / \mathrm{Mg}^{2+}$ and for the test set, cells were incubated at the indicated time with various concentrations of PX DNA (assembled in $1 \times$ TAE/Mg ${ }^{2+}$ ). Experiments were conducted as biological triplicates with separate cell culture and proliferation tests for each replicate.

\section{RNA isolation and quantitative RT-PCR (qRT-PCR)}

Total RNA was extracted using RNEasy mini kit (Qiagen) by following the manufacturer's instructions. cDNA synthesis was carried out using the iScript cDNA Kits (Bio-Rad) as instructed. Then, qRT-PCR was carried out using SYBR green PCR master mix (Bio-Rad) in a Bio-Rad thermal cycler using Myogenin (Myog) and Myosin Heavy Chain (MHC) specific primers. GAPDH primer pairs were used as housekeeping gene for normalizing the values of Myog and $\mathrm{MHC}$. 


\section{Duplex}

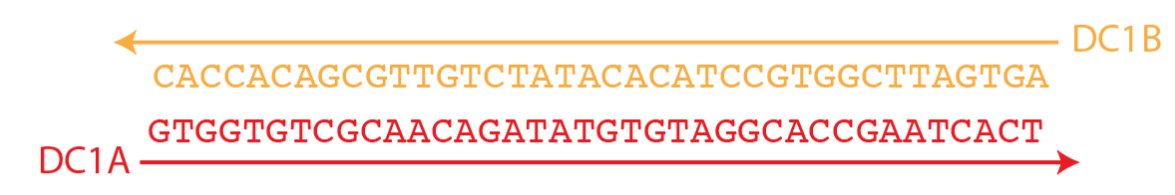

\section{DX}

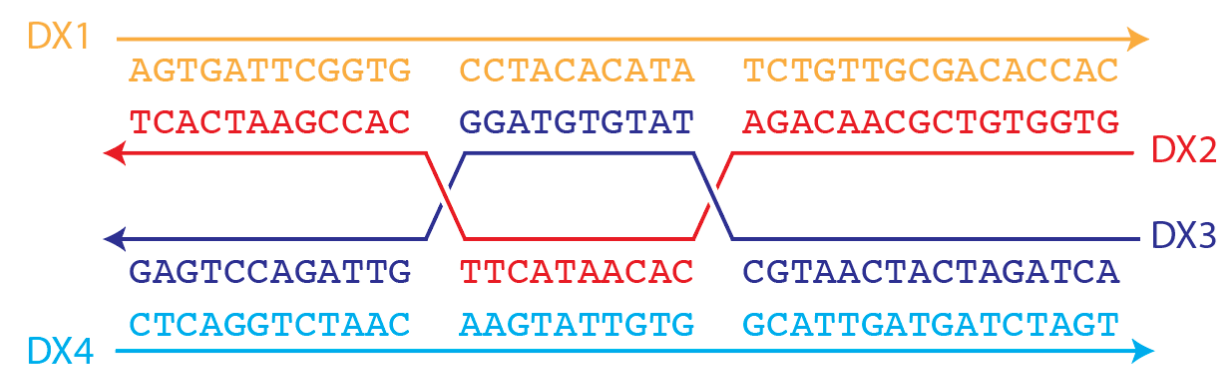

\section{PX}

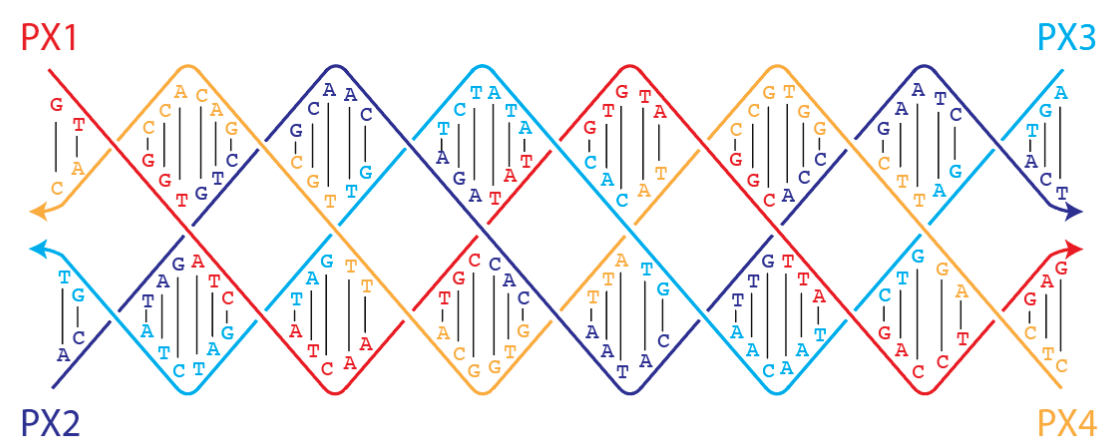

Figure S1. Design and sequences of DNA structures. Strand diagrams of duplex, DX and PX DNA motifs used in this study. Component strands are labeled in color scheme identical to that in Figure 1 of main text. Arrows indicate 3 ' ends of strands. 


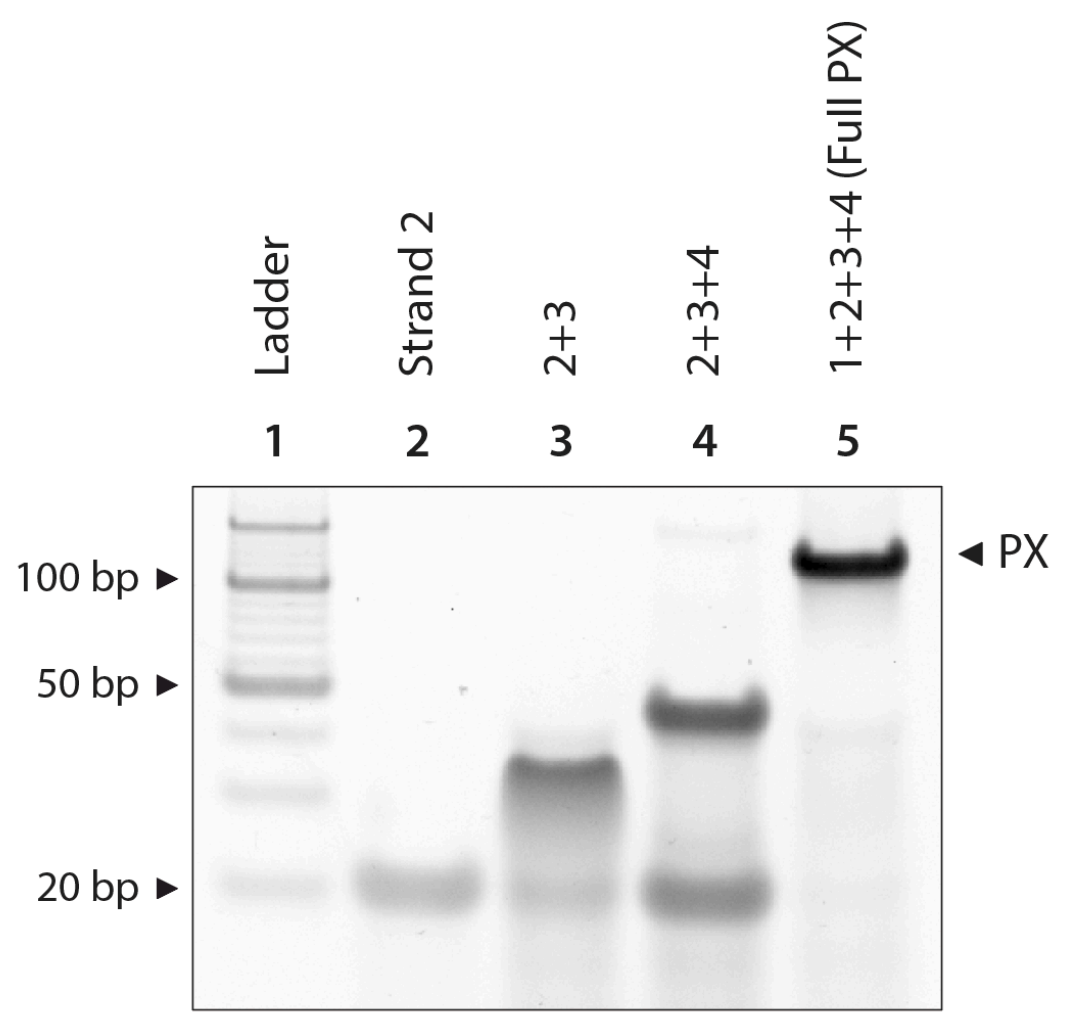

Figure S2. Stepwise assembly of PX DNA. Different number of component strands were annealed to show formation of the full PX molecule containing 4 strands. 


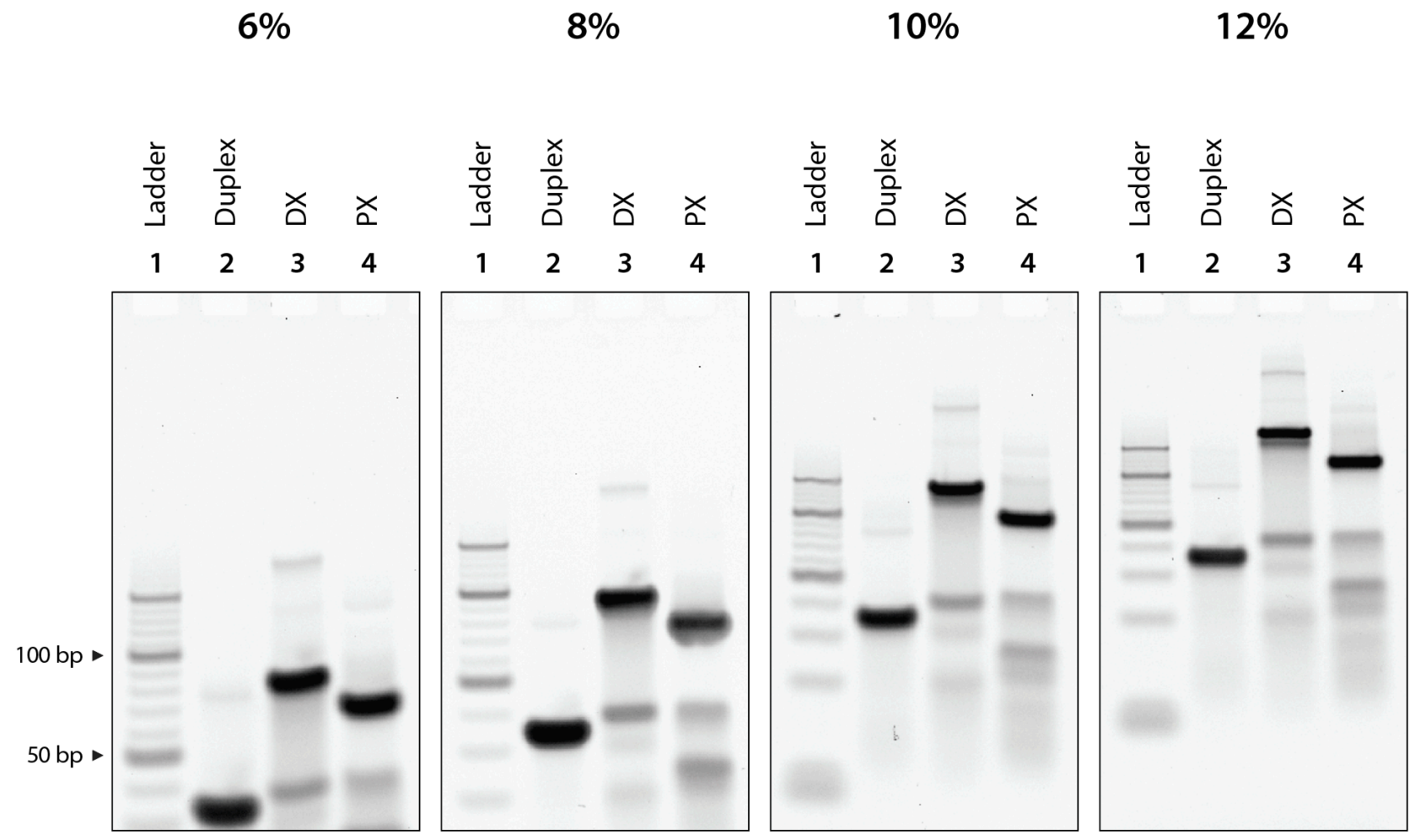

Figure S3. Ferguson plot analysis. PAGE gels of different gel percentages for Ferguson plot analysis of the three structures (duplex, DX and PX). Slopes from the Ferguson plot show that the PX motif is similar to a DX and distinct from double stranded B-DNA (described in Figure 1c in main text). 

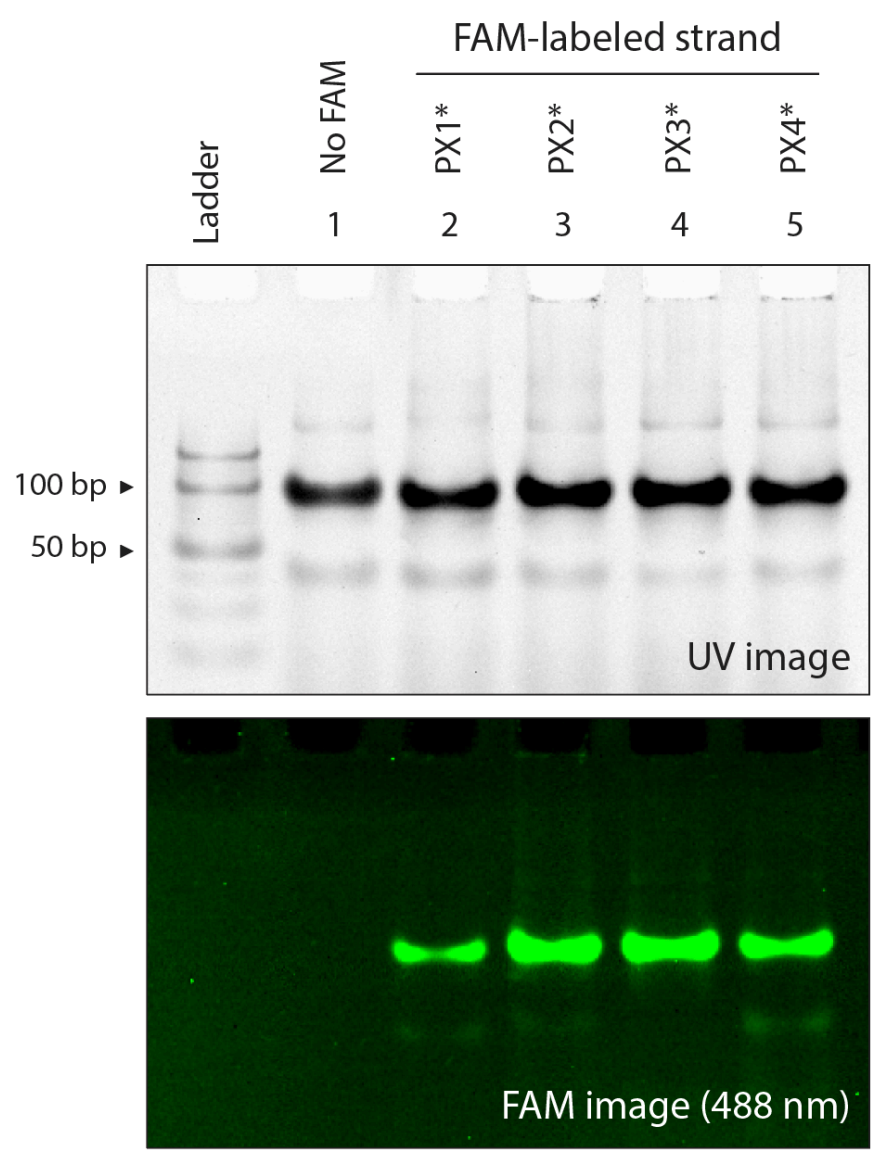

Figure S4. Strand incorporation in PX DNA. Analysis of PX formation using fluorophore-tagged component strands. Four different PX complexes were annealed where each of the four component strands were labeled with fluorescein (FAM). Non-denaturing PAGE showed that all four strands are present in the complex (lanes 2-5) compared to a non-labeled complex (lane 1). FAM-labeled strand is indicated by * in the gel labels (strand identity in Figure S1). 


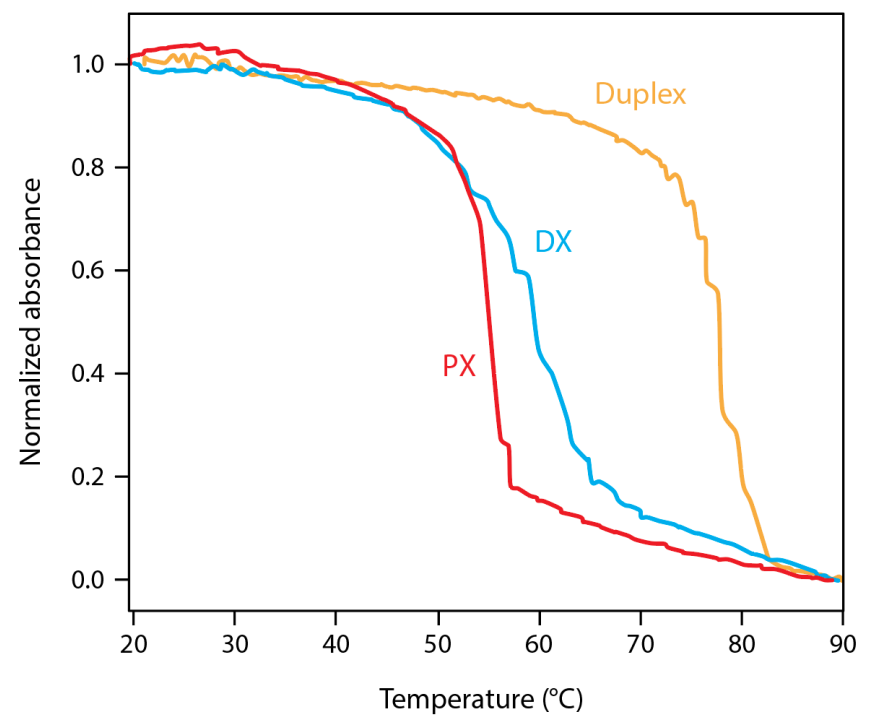

Figure S5. UV melting analysis. Melting profiles of the duplex, DX and PX structures used in this study. 


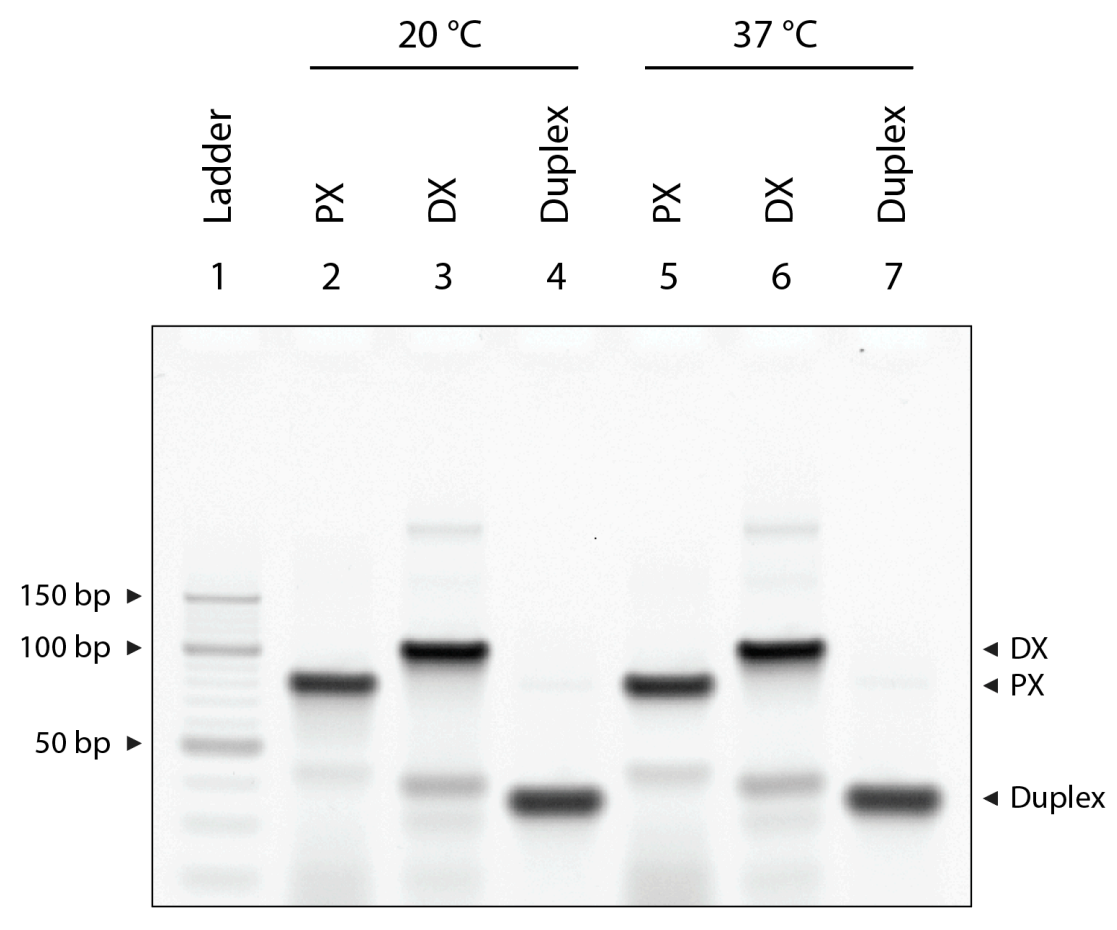

Figure S6. Stability of motifs at physiological temperature. Duplex, DX and PX motifs are intact at 37 ${ }^{\circ} \mathrm{C}$ for at least 24 hours. 
Duplex
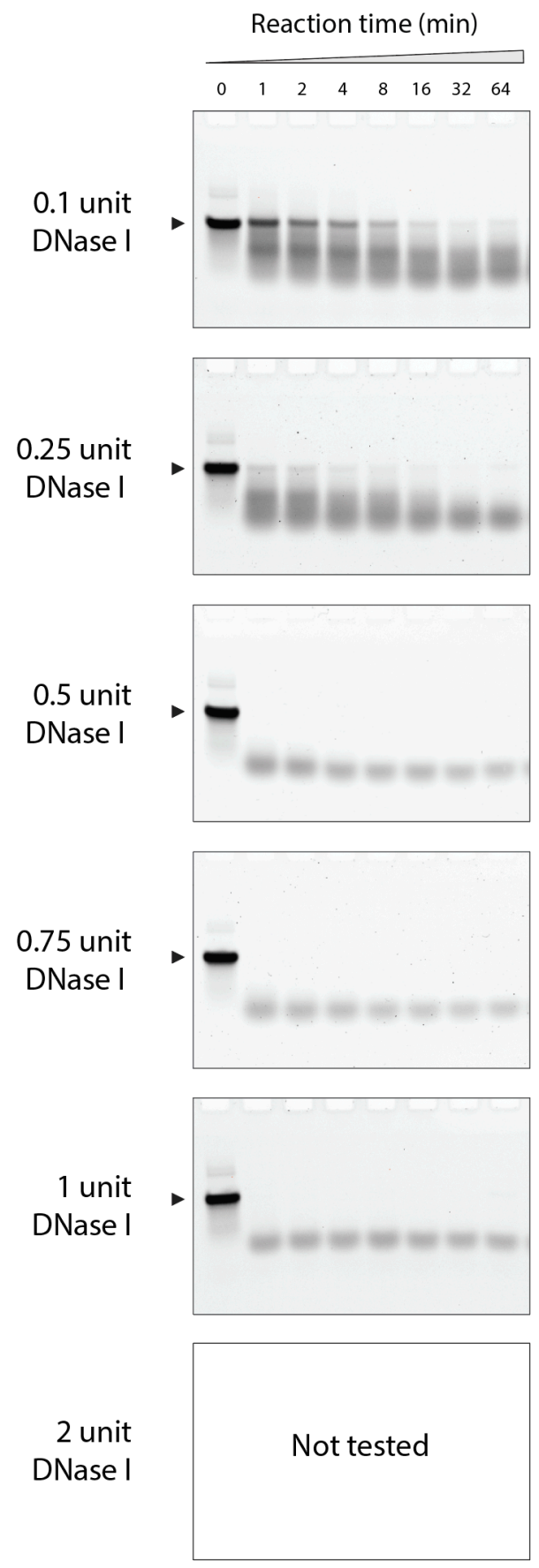

DX
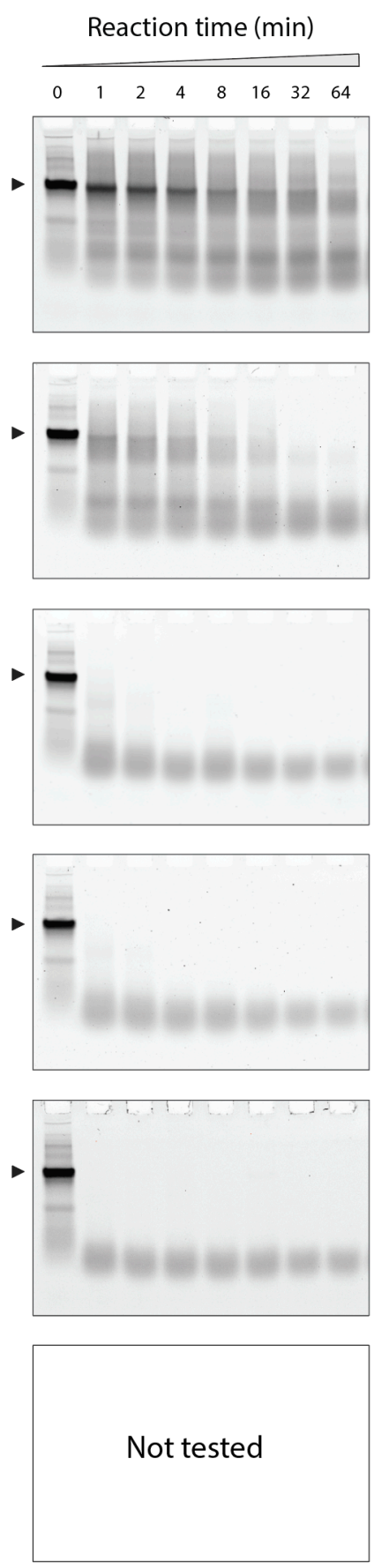

PX
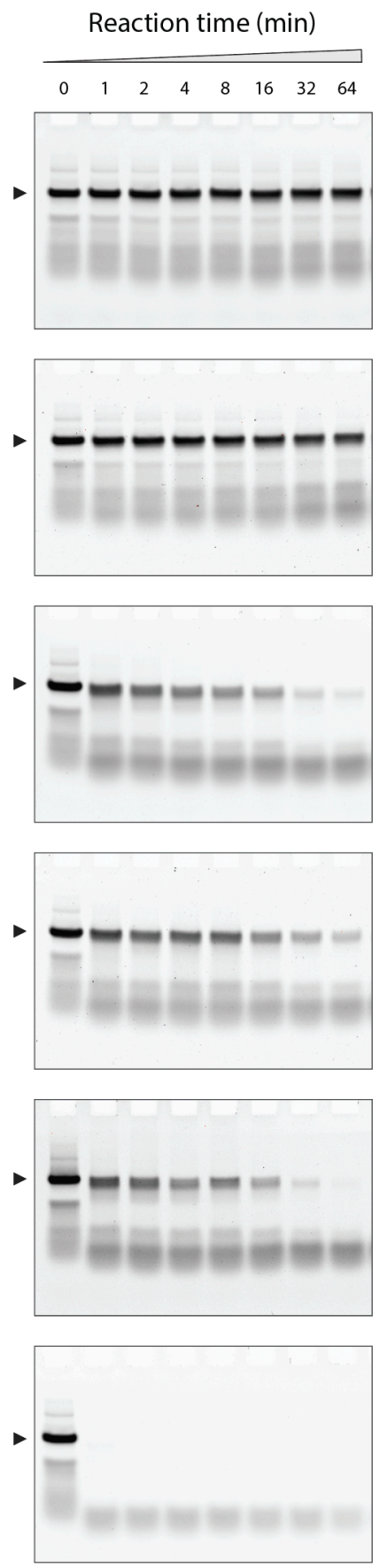

Figure S7. DNase I treatment of duplex, DX and PX motifs. Non-denaturing PAGE showing degradation of the three structures when incubated with different amounts of DNase I enzyme. 


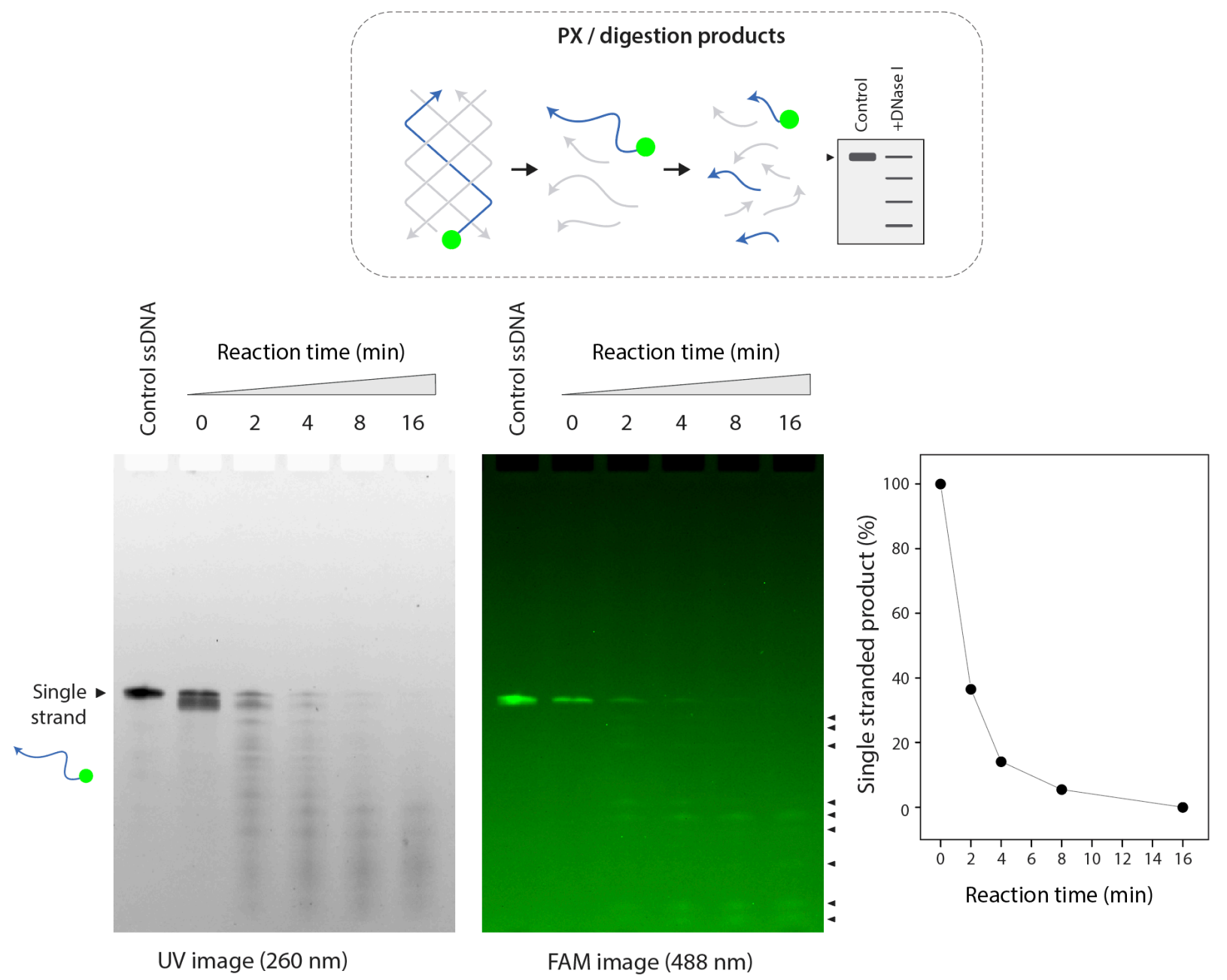

Figure S8. Digestion products PX DNA. FAM-labeled PX DNA was incubated with 1 unit DNase I and monitored by quantifying the fluorescently labeled component strand. Denaturing PAGE of DNase I treated complex shows that the single stranded products decrease over time eventually being cleaved into shorter oligos and polynucleotides. Gel was imaged under UV (left) as well as at $488 \mathrm{~nm}$ corresponding to FAM (right). Digestion products smaller than the single strand (38 nt) are indicated by arrows. 

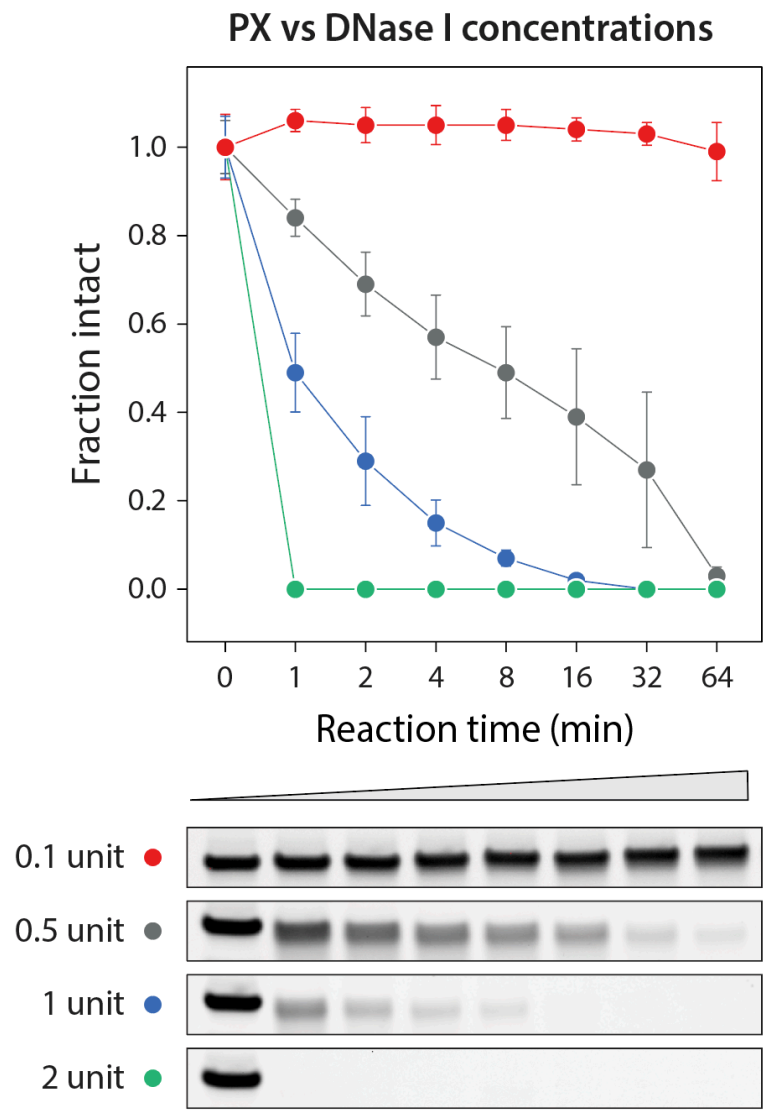

Figure 59. PX DNA resistance against DNase I. Quantitative plot and non-denaturing gels of PX DNA treated with different amounts of DNase I (enzyme amounts indicated next to gels). 


\section{Duplex}

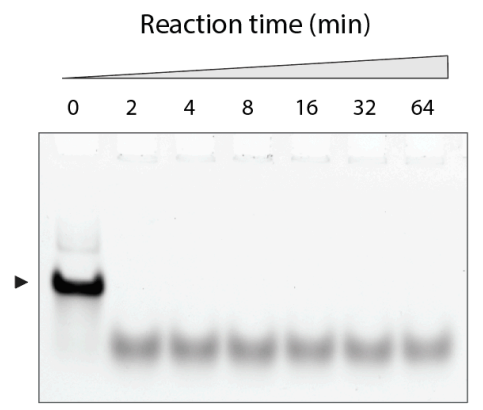

RecBCD (Exonuclease V) -- $5 \mathrm{U} / \mu \mathrm{L}$

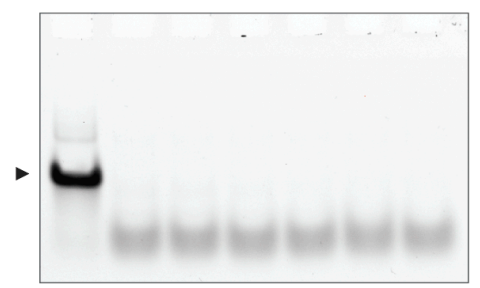

T7 Exonuclease -- $10 \mathrm{U} / \mu \mathrm{L}$

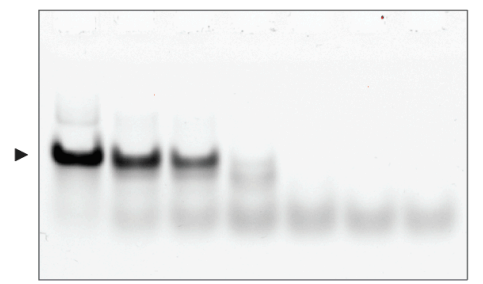

T5 Exonuclease -- $1.25 \mathrm{U} / \mu \mathrm{L}$
DX
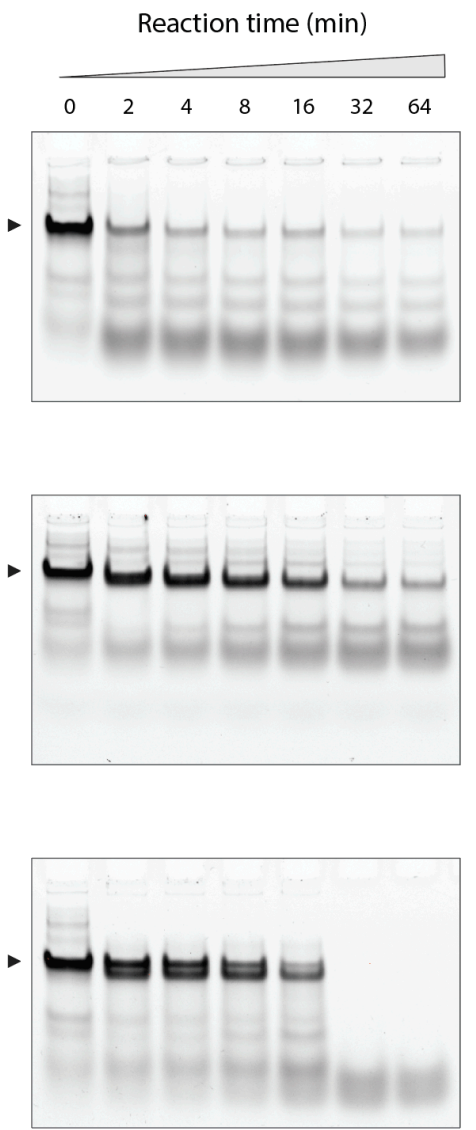

PX
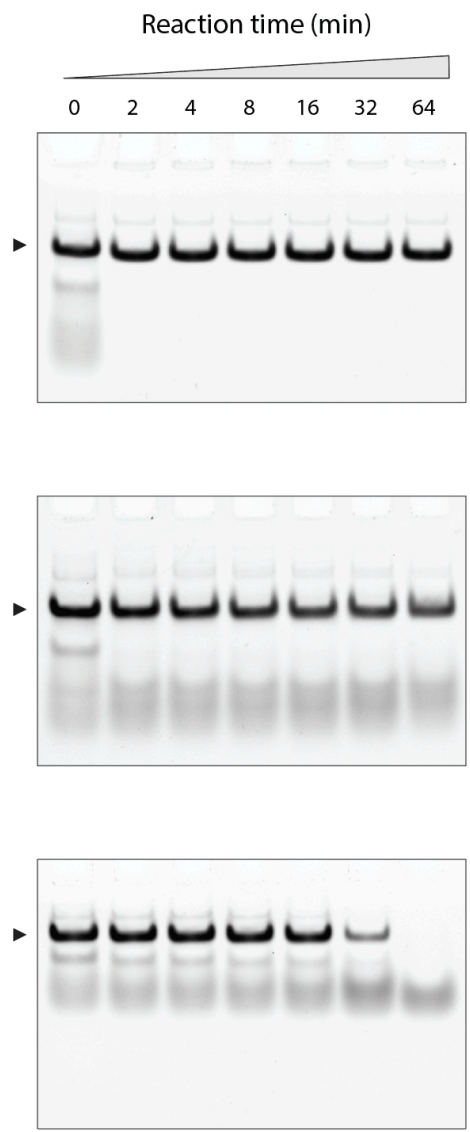

Figure S10. Resistance of tested structures to exonucleases. Full gel images of non-denaturing PAGE of duplex, DX and PX tested against RecBCD (exonuclease V), T7 and T5 exonucleases (full gels of images in Figure $2 b-2 d$ in main text). 
DNase I

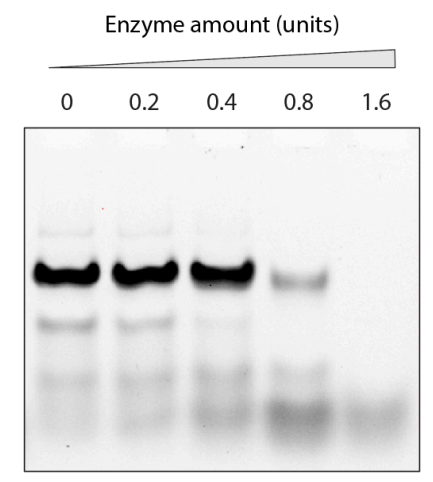

T7 exonuclease

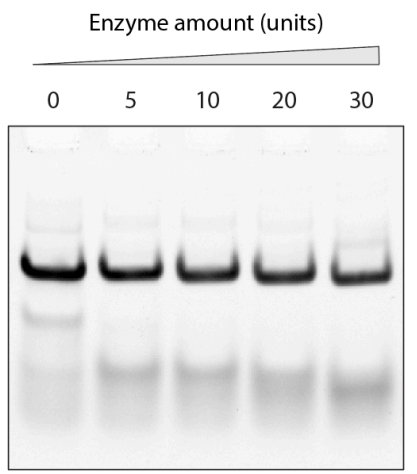

$\operatorname{RecBCD}$

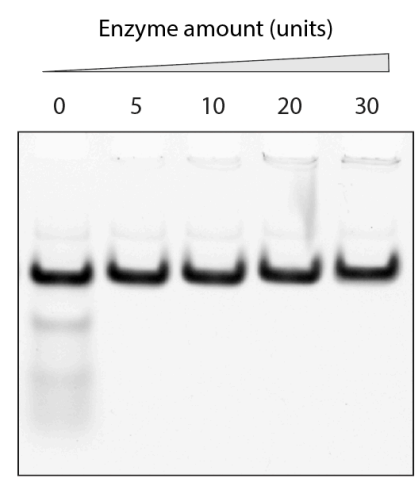

T5 exonuclease

Enzyme amount (units)

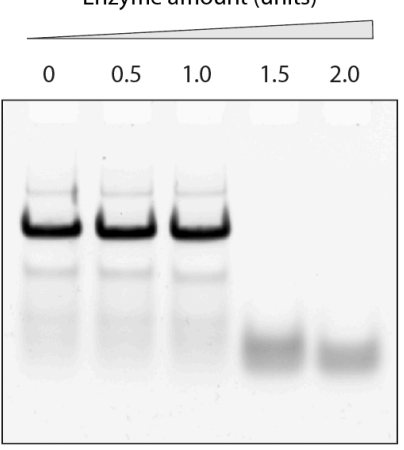

Figure S11. Enzyme activity of different nucleases on PX DNA. 


\section{DNase I (0.5 units)}

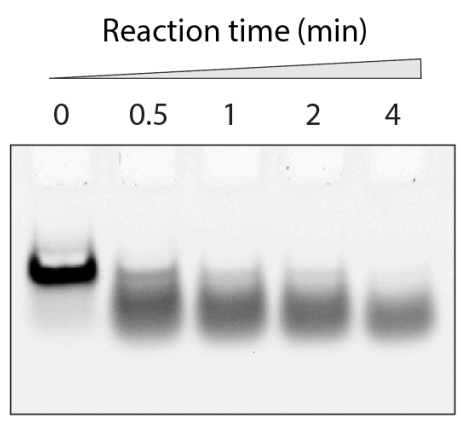

Duplex
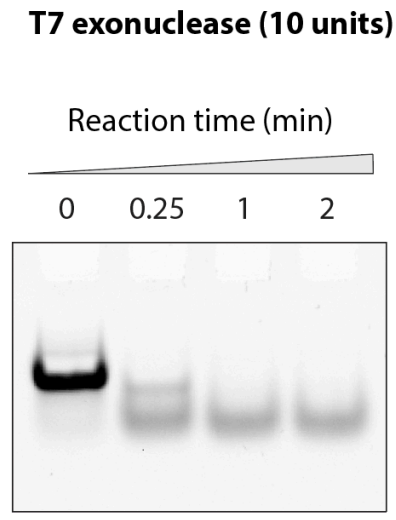

Duplex
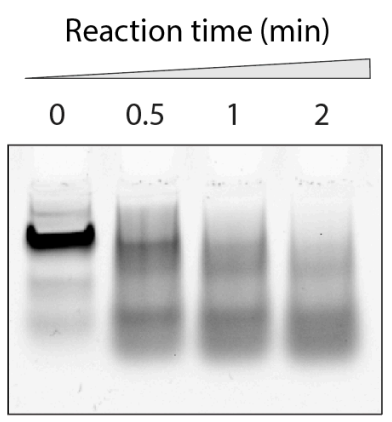

DX

RecBCD (5 units)

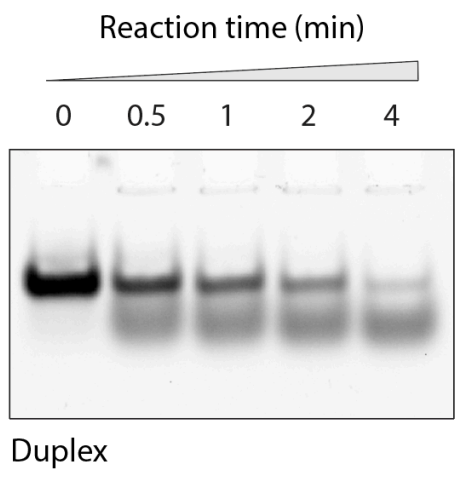

Figure S12. Analysis of shorter time points for incubation with exonucleases. Bands were quantified and fitted with an exponential decay model (shown in Figure S13). 


\section{DNase I}
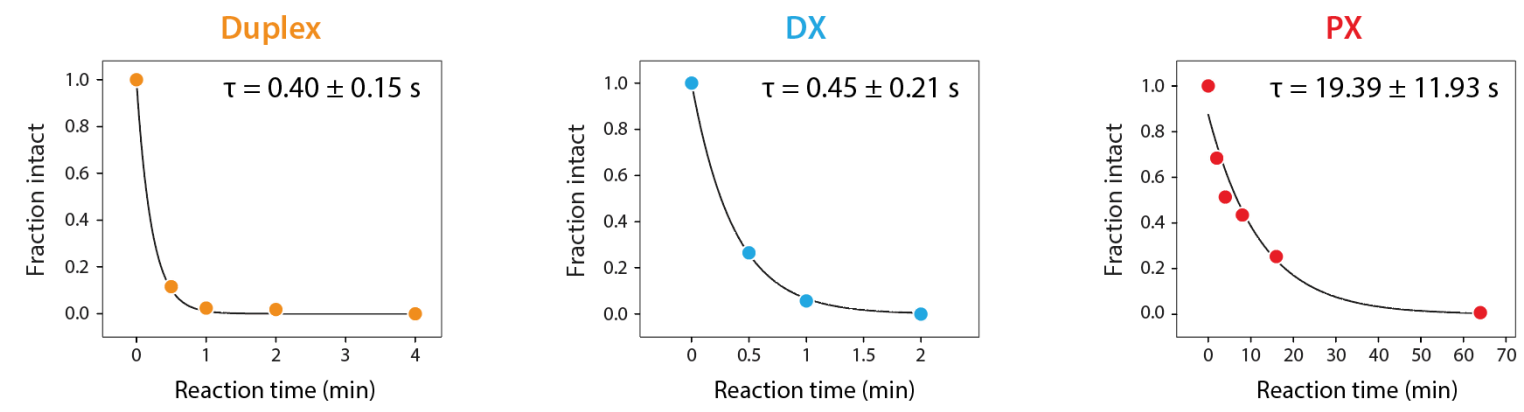

$\operatorname{RecBCD}$
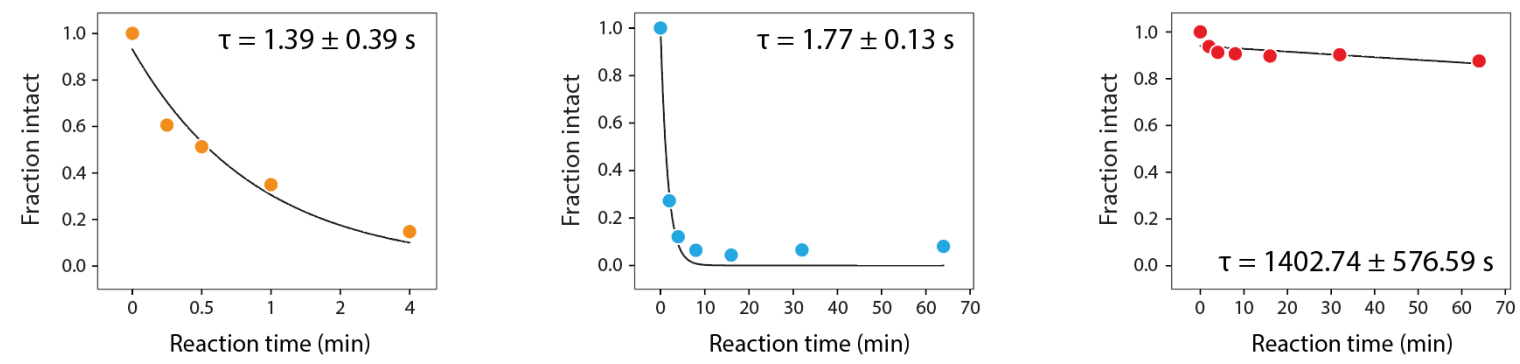

\section{T7 Exonuclease}
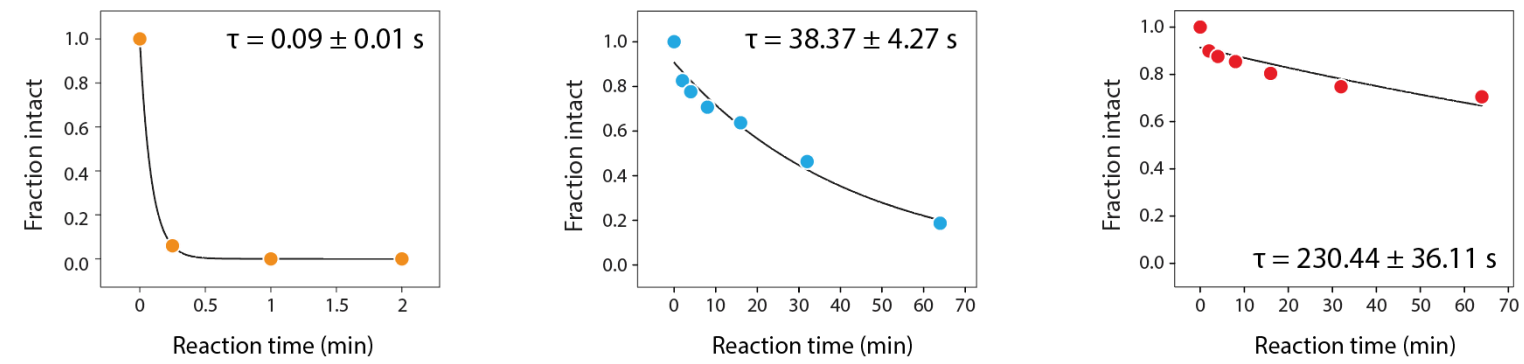

\section{T5 Exonuclease}
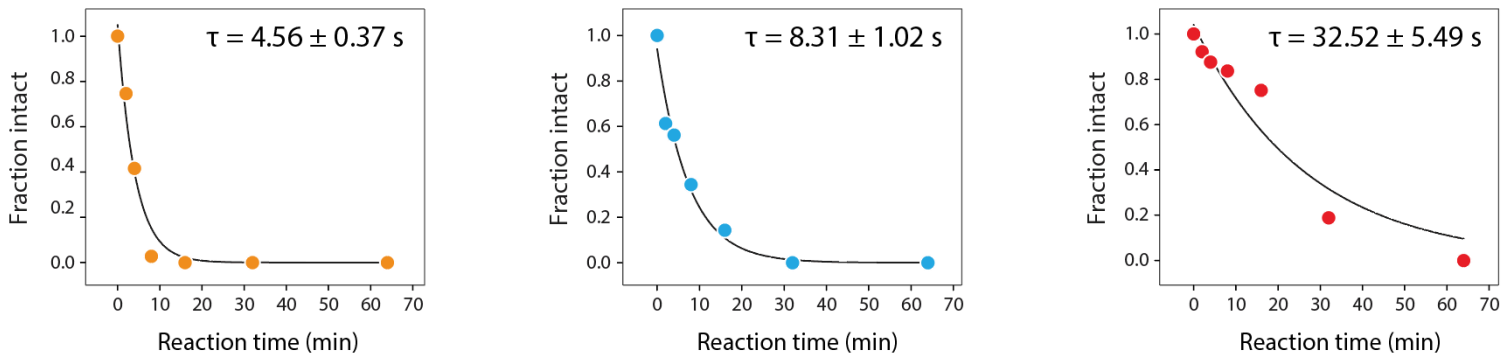

Figure S13. Decay kinetics of structures in different nucleases. Each replicate time series for duplex, DX and PX DNA incubated with a nuclease was fitted with an exponential decay model to obtain time constants. Average time constants and standard deviations calculated from three replicates is shown on the respective plots (more details in methods). 


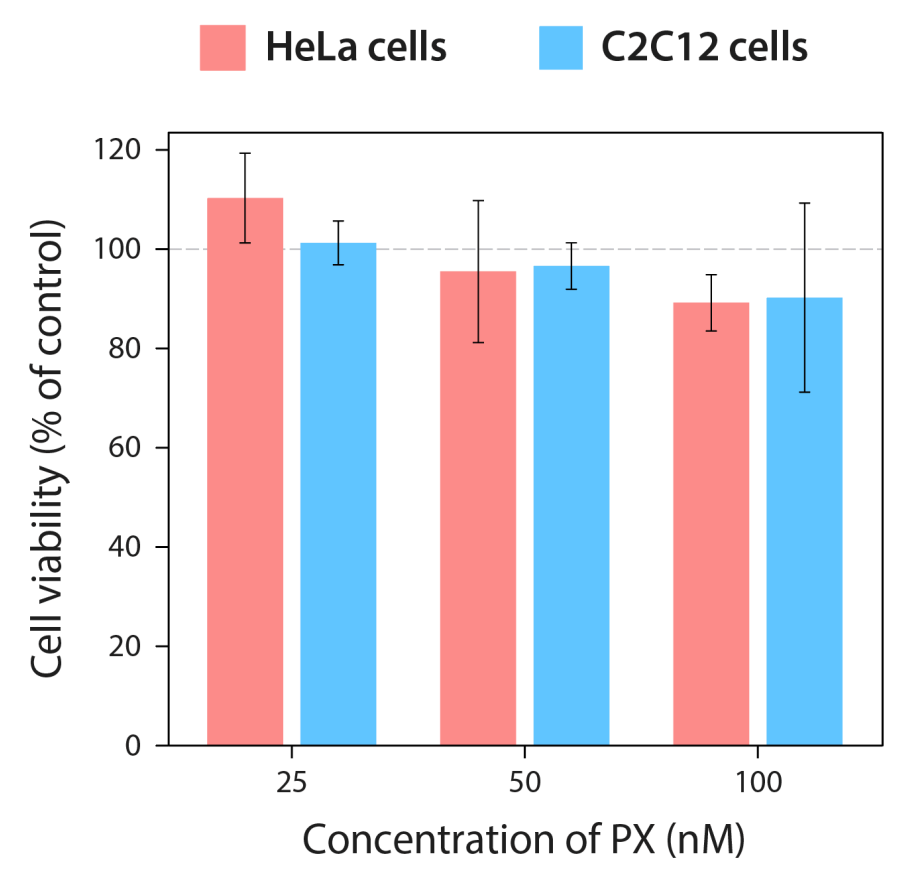

Figure S14. Cell viability with different concentrations of PX DNA. MTT assay showing cell viability after 48 hours in the presence of $25 \mathrm{nM}, 50 \mathrm{nM}$ and $100 \mathrm{nM}$ PX in HeLa and C2C12 cells. Values are normalized to the control cells incubated with $1 \times \mathrm{TAE}-\mathrm{Mg}^{2+}$ buffer (indicated by the grey line). Values presented are mean \pm standard deviation calculated from biological triplicates. 

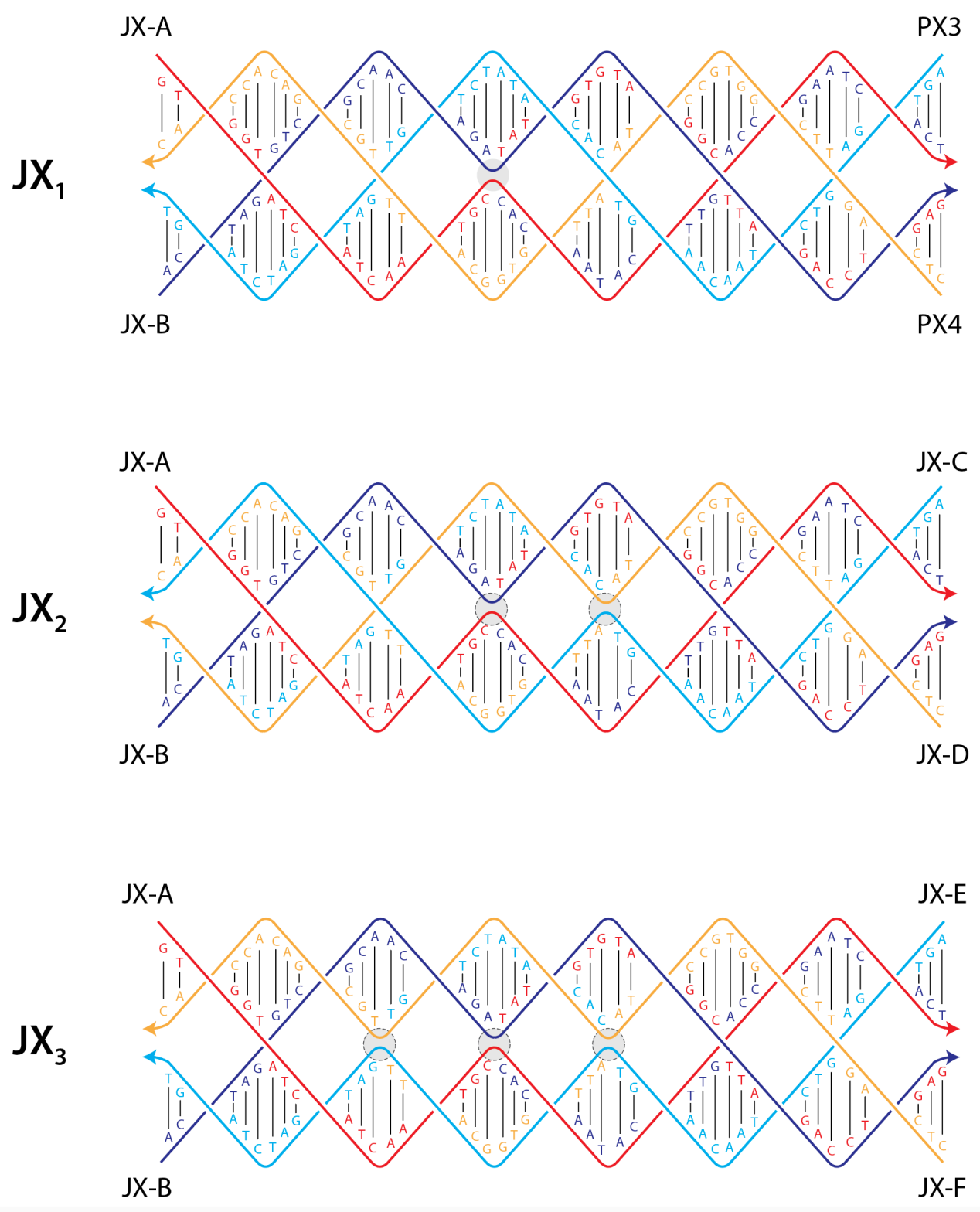

Figure S15. Design and sequences of the $J X_{n}$ DNA motifs. Strand diagrams of $J X_{1}, J X_{2}$ and $J X_{3}$ motifs. Component strands are shown in the same four colors in each motif for clarity, but the strands required to form the motifs have different sequences (as indicated by the strand name). Arrows indicate 3 ' ends of strands. 


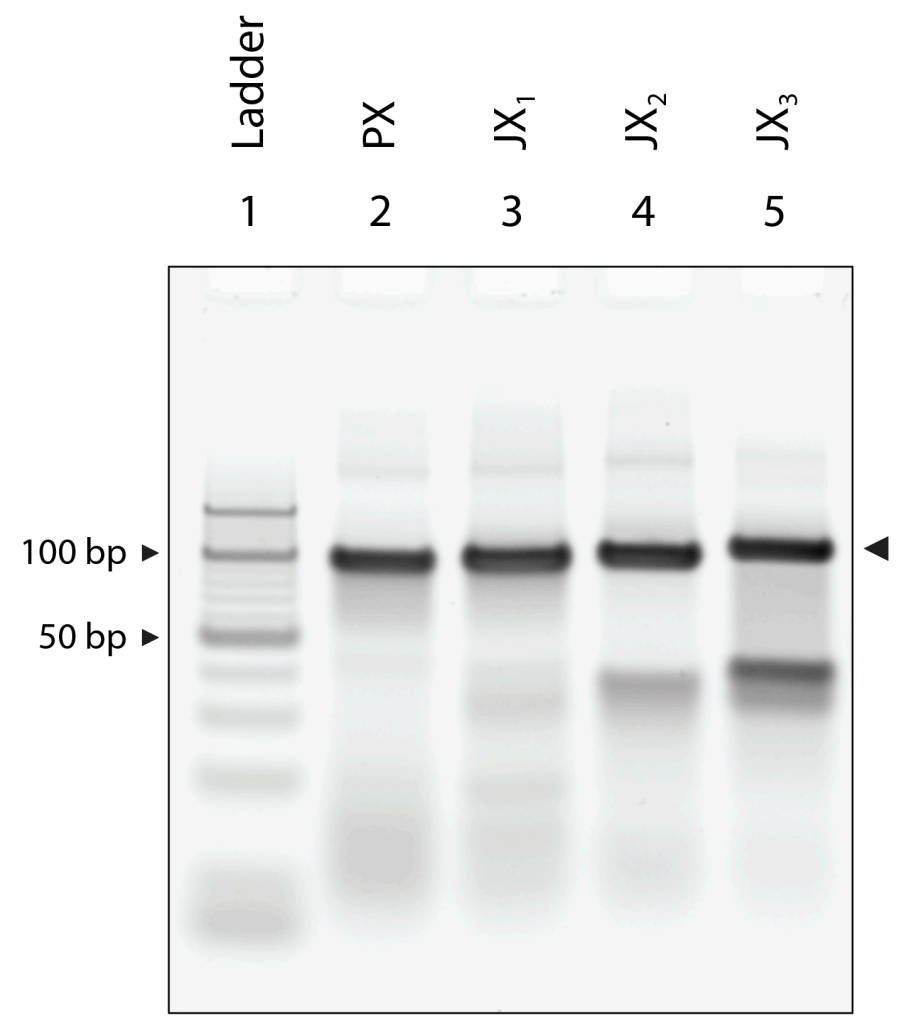

Figure S16. Assembly of $\mathrm{JX}_{\mathrm{n}}$ motifs. Non-denaturing PAGE showing the formation of $\mathrm{JX}_{1}, \mathrm{JX}_{2}$ and $\mathrm{JX}_{3}$ structures. 


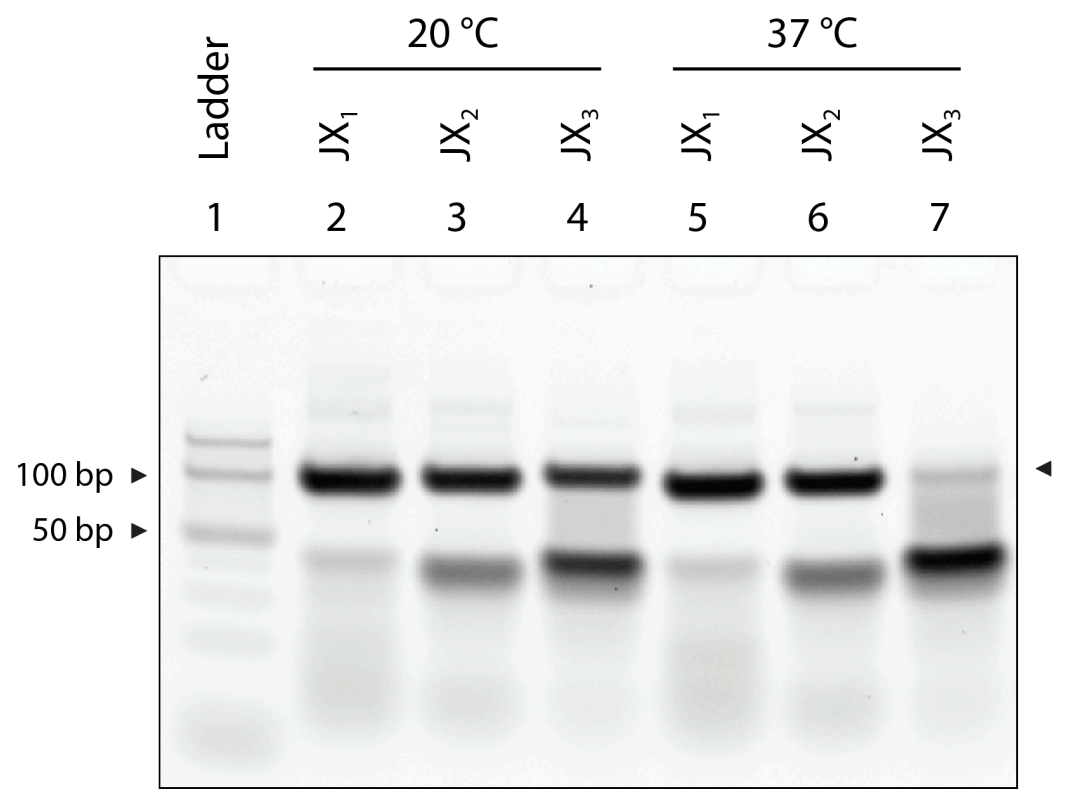

Figure S17. Stability of $\mathrm{JX}_{\mathrm{n}}$ motifs at $37^{\circ} \mathrm{C}$. $\mathrm{JX}$ and $\mathrm{JX}$ structures are stable at $37^{\circ} \mathrm{C}$ for 2 hours while the $\mathrm{JX}_{3}$ motif is degraded. 

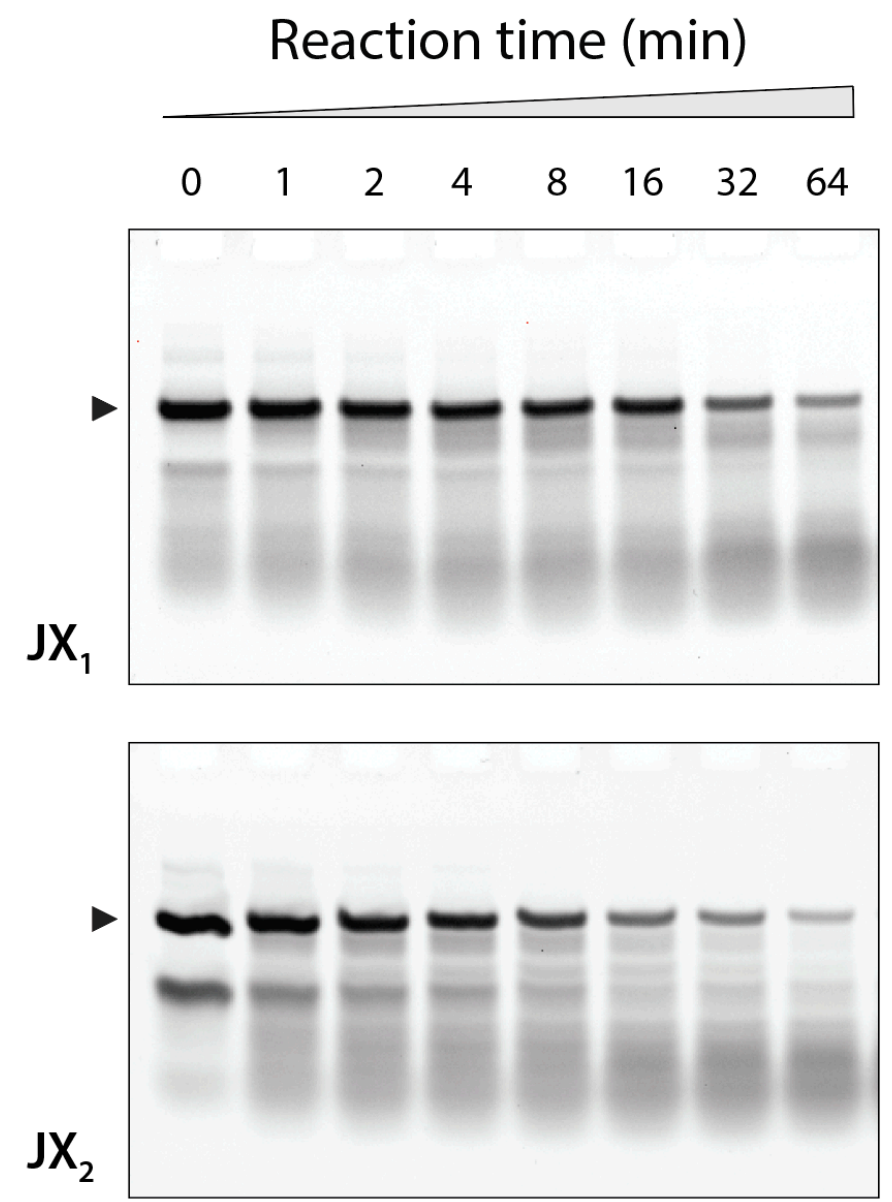

Figure S18. DNase I resistance of $\mathrm{JX}_{\mathrm{n}}$ motifs. Non-denaturing PAGE showing degradation of $\mathrm{JX}_{1}$ and $\mathrm{JX}_{2}$ structures when incubated with 0.1 unit DNase I enzyme (also shown in Figure 5a in main text). 


\section{Duplex}

Reaction time (h)

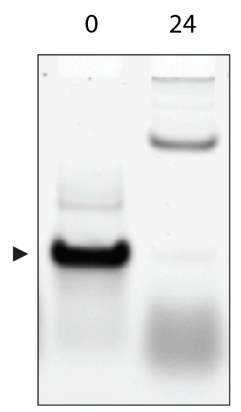

DX
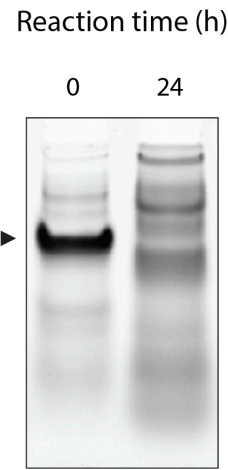

PX

Reaction time (h)

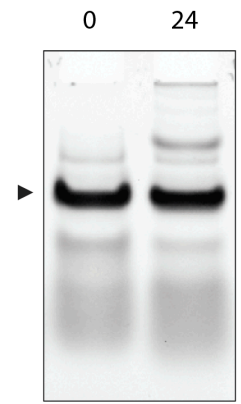

$\mathrm{JX}$

Reaction time $(\mathrm{h})$

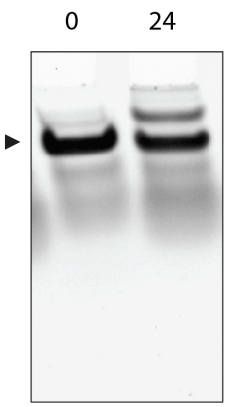

$\mathrm{JX}_{2}$

Reaction time (h)

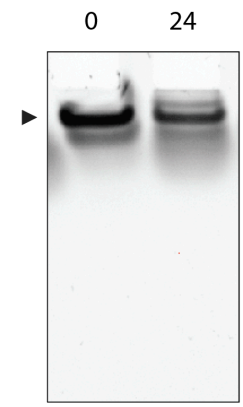

Figure S19. Stability in fetal bovine serum (FBS). Full gel images of non-denaturing PAGE showing structures incubated in 10\% FBS (also shown in Figure $5 \mathrm{~b}$ in main text). 


\section{Human serum}
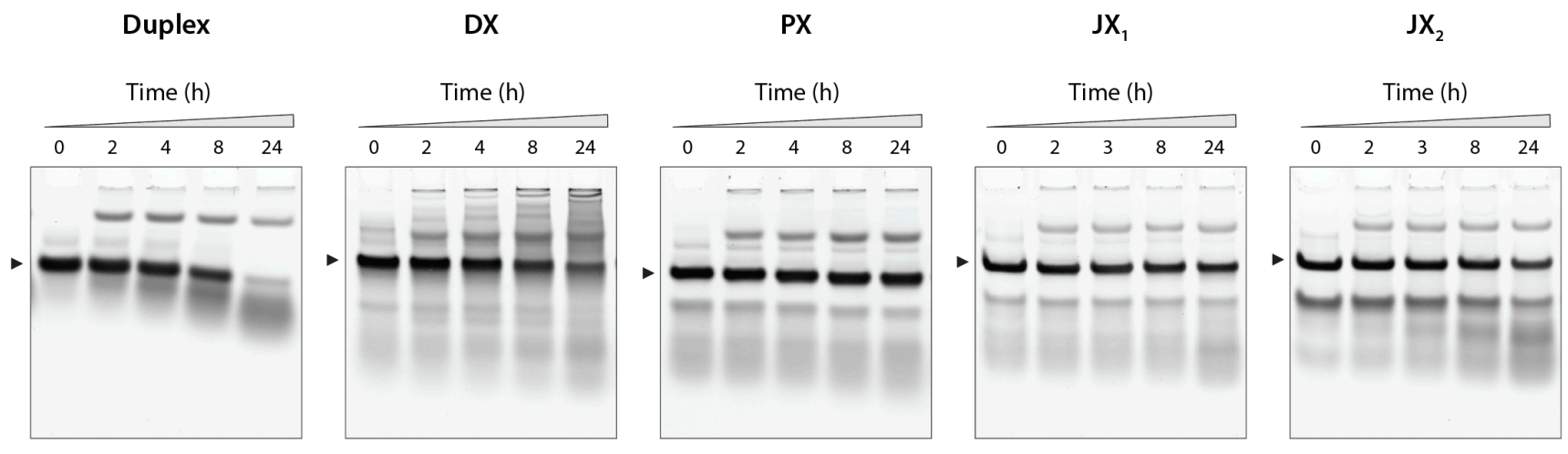

\section{Human urine}
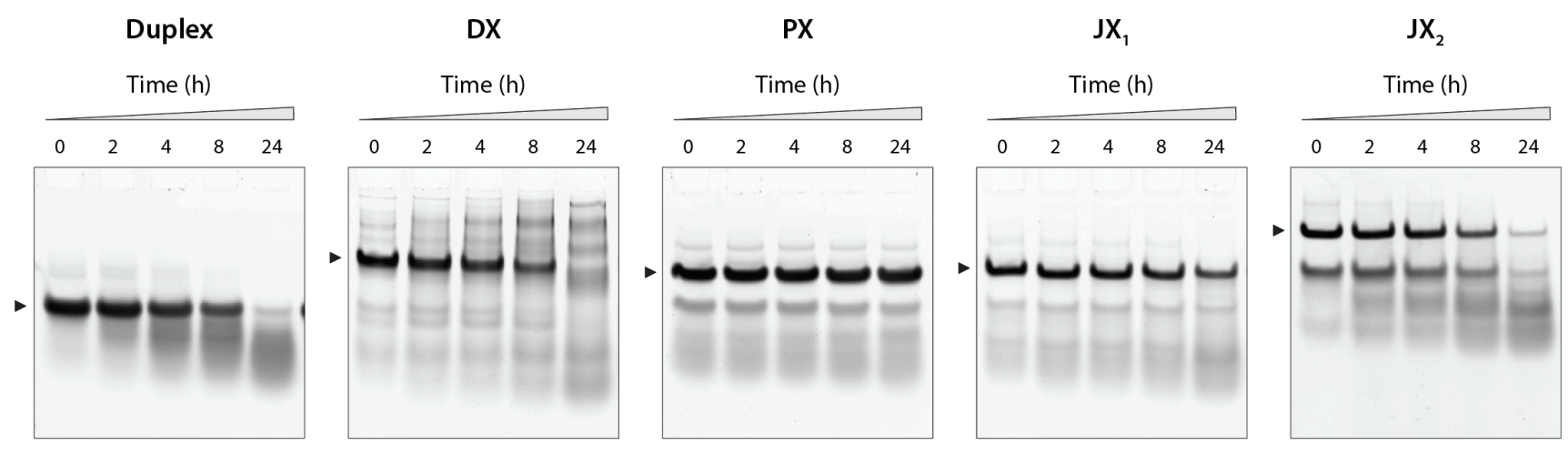

Figure S20. Stability in human serum and urine. Full gel images of non-denaturing PAGE showing stability of structures in human serum (top) and human urine (bottom). Consolidated analysis is shown in Figure $5 c-d$ in main text. 


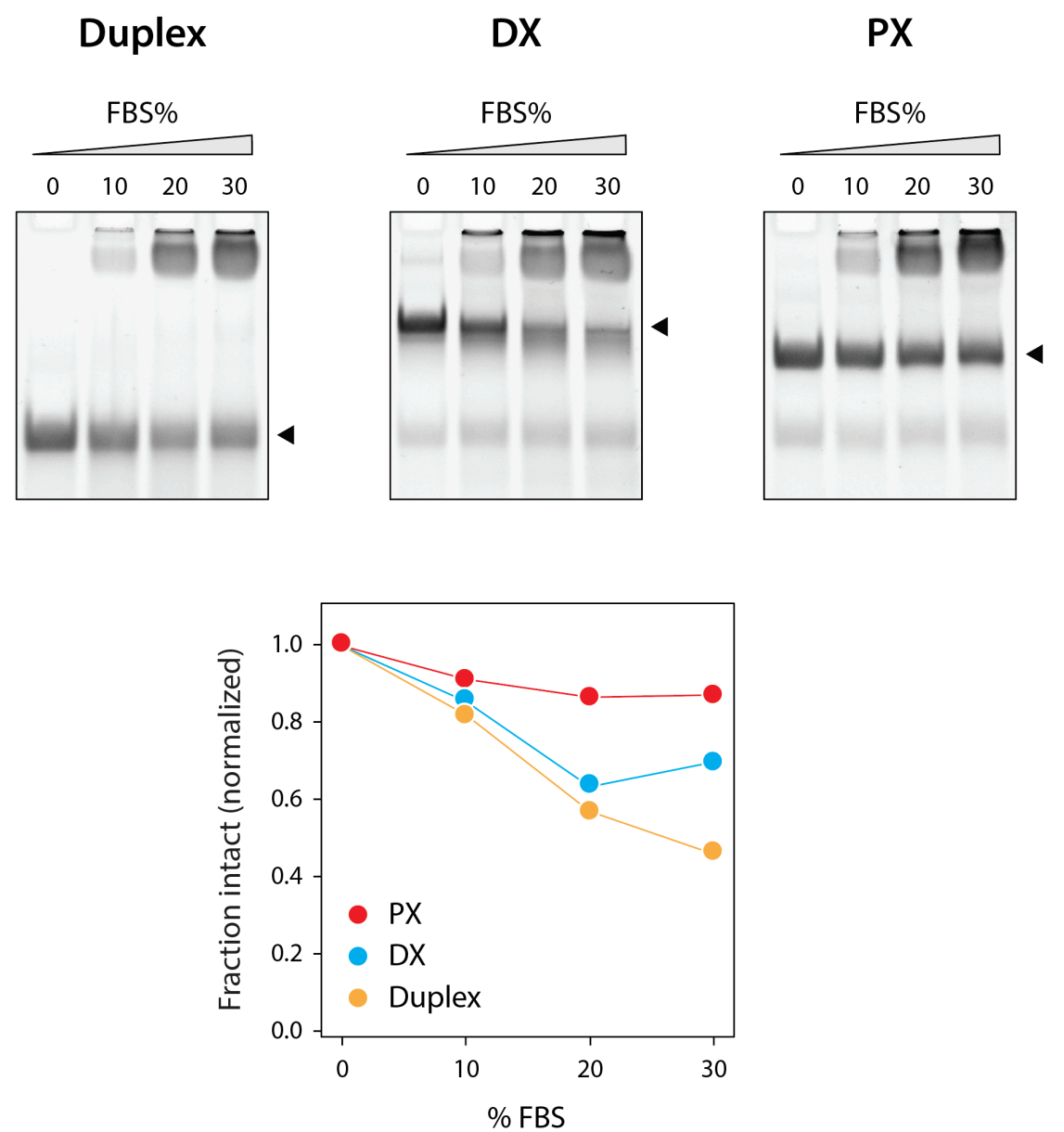

Figure S21. Stability of duplex, DX and PX motifs incubated in different amounts of FBS for 1.5 hours. 